\title{
Understanding the effects of different HIV transmission models in individual-based microsimulation of HIV epidemic dynamics in people who inject drugs
}

\author{
J. F. G. MONTEIRO ${ }^{1,2} *$, D. J. ESCUDERO ${ }^{1}$, C. WEINREB $^{1}$, T. FLANIGAN $^{2}$, \\ S. GALEA ${ }^{3}$, S. R. FRIEDMAN ${ }^{4}$ AND B. D. L. MARSHALL ${ }^{1}$ \\ ${ }^{1}$ School of Public Health, Brown University, Providence, RI, USA \\ ${ }^{2}$ Division of Infectious Diseases, The Miriam Hospital, Providence, RI, USA \\ ${ }^{3}$ School of Public Health, Boston University, Boston, MA, USA \\ ${ }^{4}$ Institute for Infectious Disease Research, National Development and Research Institutes Inc., New York, NY, USA
}

Received 29 April 2015; Final revision 11 November 2015; Accepted 30 November 2015; first published online 12 January 2016

\section{SUMMARY}

We investigated how different models of HIV transmission, and assumptions regarding the distribution of unprotected sex and syringe-sharing events ('risk acts'), affect quantitative understanding of HIV transmission process in people who inject drugs (PWID). The individualbased model simulated HIV transmission in a dynamic sexual and injecting network representing New York City. We constructed four HIV transmission models: model 1, constant probabilities; model 2, random number of sexual and parenteral acts; model 3, viral load individual assigned; and model 4, two groups of partnerships (low and high risk). Overall, models with less heterogeneity were more sensitive to changes in numbers risk acts, producing HIV incidence up to four times higher than that empirically observed. Although all models overestimated HIV incidence, micro-simulations with greater heterogeneity in the HIV transmission modelling process produced more robust results and better reproduced empirical epidemic dynamics.

Key words: Condom use, HIV, individual-based model, Monte Carlo simulation.

\section{INTRODUCTION}

HIV transmission between serodiscordant sexual and injecting partners is determined in part by the per-act HIV transmission probability, and by the number of unprotected sex and/or syringe-sharing events within partnerships [1-5]. However, prior modelling work has found that the simple binomial model for perpartnership transmission probabilities (with a constant per-act transmission probability) may provide an unsatisfactory model of HIV transmission, and is unable to reproduce HIV incidence and prevalence estimates

\footnotetext{
* Author for correspondence: Dr J. F. G. Monteiro, School of Public Health, Brown University, 121 South Main Street, Box GS-121-2, Providence, RI 02912, USA.

(Email: filipemuks@gmail.com)
}

observed in most settings [6]. Two major concerns have been raised with the binomial model for HIV transmission between serodiscordant partners. First, substantial heterogeneity in HIV susceptibility/infectiousness has been observed for both sexual and parenteral transmission pathways [1, 5, 7-11]. Second, homogeneous transmission models (i.e. those that assume a constant per-act transmission probability) produce inadequate infectivity estimates as suggested by observed data [12], and are misrepresentative of true risks associated with heterosexual contact. In part, these discrepancies are a manifestation of the assumption of independence between transmission risk and number of exposures [12].

Despite the fact that binomial models of HIV transmission are known to be inadequate, few studies have been conducted to develop, examine, and validate 
more sophisticated models of HIV transmission associated with injecting behaviour. This suggests that further work is needed to better estimate transmission probabilities related to contaminated injections and their likely contribution to overall HIV transmission in people who inject drugs (PWID) [13]. Finally, HIV infectiousness is known to vary substantially during the course of HIV infection (being higher during primary infection and in advanced disease), and also among persons in clinical latency [14, 15]. Therefore, further investigation is required to improve mathematical modelling efforts to reproduce and understand the HIV transmission process, particularly in PWID.

Individual-based models are an increasingly common method to better understand HIV transmission dynamics and evaluate HIV treatment and prevention interventions [16-19]. In contrast to compartmental models, individual-based microsimulations permit the analysis of interacting heterogeneous individuals and their behaviours in diverse environments [16-21]. Despite their increasing popularity in HIV research, the core model structures and processes that produce meaningful and valid outputs remain poorly understood [22]. A recently published systematic review on individual-based modelling of HIV transmission concluded that there is need for more consistent evaluation and explicit comparison of HIV transmission models to increase confidence in existing and future modelling results [23]. Here, we compare the validity of increasingly sophisticated (i.e. more complicated) models for HIV transmission among PWID in a North American setting, and how different models affect quantitative understanding and simulation of the HIV transmission process.

\section{MATERIAL AND METHODS}

We used an individual-based model, previously calibrated to be representative of the adult population (i.e. aged 15-59 years) of the New York metropolitan statistical area (MSA) [24-34]. This model therefore reproduces an urban, mixed HIV epidemic in which multiple low- and high-risk groups [i.e. PWID, men who have sex with men (MSM)] interact, and in which several modes of HIV transmission (vaginal, anal, parenteral) are present. This urban population within an established mixed epidemic is well studied $[18,24,35-37]$ and serves well for our investigation in accounting for heterogeneity in HIV transmission, by comparing the different groups at risk (i.e. PWID and non-drug users). In order to account for
Table 1. Initial population distribution of the individual-based model (row percentages)

\begin{tabular}{llllr}
\hline \hline & \multicolumn{2}{l}{ Male } & \multicolumn{2}{l}{ Female } \\
\cline { 2 - 3 } Population group & MSM & HM & HF & Total \\
\hline PWID & $6 \cdot 5$ & $58 \cdot 7$ & $34 \cdot 8$ & $1 \cdot 2$ \\
PWUD & $7 \cdot 3$ & $53 \cdot 2$ & $39 \cdot 5$ & $6 \cdot 5$ \\
Non-drug user & $2 \cdot 2$ & $46 \cdot 9$ & $50 \cdot 9$ & $92 \cdot 3$ \\
Total & $2 \cdot 6$ & $47 \cdot 4$ & $50 \cdot 0$ & $100 \cdot 0 \%$ \\
\hline \hline
\end{tabular}

HM, Heterosexual male; HF, heterosexual female; MSM, men who have sex with men; PWID, people who inject drugs; PWUD, people who use drugs.

Proportions estimated from: [24-34].

differences in transmission risk across HIV disease stages, the microsimulation proceeds through discrete monthly time steps, thus simulating transmission during acute, latent, and AIDS stages of the disease. In this analysis, we used the same parameter values as were coded in the existing model $[28,36,38-46]$, but observed changes in estimated HIV incidence after incorporating increasing heterogeneity in the models for HIV transmission and engagement in agent risk behaviour. Key parameters and other relevant data sources have been described in detail previously $[18,20]$.

To parameterize the individual-based model, we used previously collected empirical data [47], and an iterative indirect approach that has been described in detail previously [48]. First, we identified which realworld phenomena we were interested in reproducing (i.e. drug use prevalence, HIV prevalence/incidence, etc.), and successively developed a conceptual framework to guide the selection of processes and behaviours that would be modelled in the agent-based environment as described in Marshall et al. [20]. As a second step, we constructed a model that reflected known empirical and experimental evidence about these behaviours (see Tables 1-3). The parameter values in these tables represent point estimates (or in some cases, summary estimates) from relevant literature that were applied to the conceptual model structures for models 1-4. The relative ability of each conceptual model to reproduce estimates close to empirically observed HIV incidence and prevalence trajectories (providing information on which model structure has greatest validity) was of primary interest. Although extensive calibration procedures may theoretically enable each model type to reproduce empirical results for HIV incidence and prevalence, our goal 
Table 2. Initial parameter estimates and data sources for PWID (non-drug users) (PWUD) individuals

\begin{tabular}{|c|c|c|c|c|}
\hline \multirow[b]{2}{*}{ Variable } & \multicolumn{3}{|l|}{ Base estimate } & \multirow[b]{2}{*}{ Source [ref.] } \\
\hline & MSM & HM & $\mathrm{HF}$ & \\
\hline \multicolumn{5}{|l|}{ Demographics } \\
\hline HIV prevalence (\%) & $22 \cdot 0(15 \cdot 0)[28 \cdot 0]$ & $12 \cdot 0(1 \cdot 2)[28 \cdot 0]$ & $12 \cdot 0(1 \cdot 2)[7 \cdot 0]$ & $\begin{array}{l}{[28,29,35,38,46,} \\
49-54]\end{array}$ \\
\hline AIDS prevalence $(\%)$ & $13 \cdot 0(7 \cdot 0)[13 \cdot 0]$ & $7 \cdot 0(7 \cdot 0)[13 \cdot 0]$ & $7 \cdot 0(7 \cdot 0)[4 \cdot 0]$ & {$[11,54,55]$} \\
\hline $\begin{array}{l}\text { Proportion of HIV positive } \\
\text { individuals on ART }(\%)\end{array}$ & $20 \cdot 0(30 \cdot 0)[14 \cdot 0]$ & $20 \cdot 0(25 \cdot 0)$ & {$[14 \cdot 0]$} & {$[56-59]$} \\
\hline \multicolumn{5}{|l|}{$\begin{array}{l}\text { All-cause mortality rate (per } 10000 \\
\text { person-months) }\end{array}$} \\
\hline In HIV-negative individuals & & $13(4)[6]$ & & {$[60-63]$} \\
\hline $\begin{array}{l}\text { In HIV-positive individuals, not on } \\
\text { ART }\end{array}$ & & $83(33)$ [33] & & {$[11,63-65]$} \\
\hline $\begin{array}{l}\text { In HIV-positive individuals, on } \\
\text { ART }\end{array}$ & & $17(8)[10]$ & & {$[11,63,66-69]$} \\
\hline $\begin{array}{l}\text { In individuals diagnosed with } \\
\text { AIDS }\end{array}$ & & $67(67)[67]$ & & {$[11,66,67,70-72]$} \\
\hline \multicolumn{5}{|l|}{ Risk behaviours } \\
\hline $\begin{array}{l}\text { Unprotected intercourse* (monthly } \\
\text { probability) }\end{array}$ & $0 \cdot 75$ & $(0 \cdot 40)[0 \cdot 55]$ & $0 \cdot 75(0 \cdot 70)[0 \cdot 85]$ & {$[28,36,38-46]$} \\
\hline $\begin{array}{l}\text { Reduction in sexual risk following } \\
\text { HIV + test }(\%)\end{array}$ & $10 \cdot 0$ & $(10 \cdot 0)[10 \cdot 0]$ & $40 \cdot 0(50 \cdot 0)[40 \cdot 0]$ & {$[58,73-77]$} \\
\hline $\begin{array}{l}\text { Syringe sharing } \dagger \text { (monthly } \\
\text { probability) }\end{array}$ & & $0 \cdot 20$ & & {$[29,46,78]$} \\
\hline $\begin{array}{l}\text { Reduction in injecting risk with SA } \\
\text { treatment }(\%)\end{array}$ & & $50 \cdot 0$ & & {$[79,80]$} \\
\hline $\begin{array}{l}\text { Drug use cessation (monthly } \\
\text { probability) }\end{array}$ & & $0 \cdot 0014[0 \cdot 0014]$ & & [81] \\
\hline \multicolumn{5}{|l|}{ Network parameters } \\
\hline $\begin{array}{l}\text { Behaviour with partner(s) (monthly } \\
\text { probability) }\end{array}$ & & & & {$[82,83]$} \\
\hline Sexual activity exclusively & & $0 \cdot 20$ & & \\
\hline Injecting activity exclusively & & $0 \cdot 60$ & & \\
\hline Sexual and injecting activity & & $0 \cdot 20$ & & \\
\hline Assortative mixing: (\%) & $50 \cdot 0$ & $(90 \cdot 0)[90 \cdot 0]$ & $80 \cdot 0(100 \cdot 0)[50 \cdot 0]$ & {$[30,40,82-88]$} \\
\hline \multicolumn{5}{|l|}{$\begin{array}{l}\text { Substance abuse treatment (monthly } \\
\text { probability) }\end{array}$} \\
\hline $\begin{array}{l}\text { Probability of initiation, given no } \\
\text { NSP access }\end{array}$ & & $0 \cdot 0077[0 \cdot 0075]$ & & {$[89,90]$} \\
\hline $\begin{array}{l}\text { Probability of initiation, given NSP } \\
\text { access }\end{array}$ & & $0 \cdot 0161$ & & [90-92] \\
\hline $\begin{array}{l}\text { Discontinuation§ at } t=j \text {, given } \\
\text { initiation at } t<j\end{array}$ & & $0 \cdot 0556[0 \cdot 0556]$ & & {$[90,93,94]$} \\
\hline \multicolumn{5}{|l|}{$\begin{array}{l}\text { HIV testing and counselling (monthly } \\
\text { probability) }\end{array}$} \\
\hline Test for HIV, given no NSP access & & $0.0233(0 \cdot 005)[0 \cdot 005]$ & & {$[51,95-97]$} \\
\hline Test for HIV, given NSP access & & $0 \cdot 0476$ & & [96] \\
\hline \multicolumn{5}{|l|}{$\begin{array}{l}\text { HIV treatment parameters (monthly } \\
\text { probability) }\end{array}$} \\
\hline $\begin{array}{l}\text { ART initiation, given no SA } \\
\text { treatment }\end{array}$ & & $0.0069(0.0117)[0.0067]$ & & [98-100] \\
\hline ART initiation, given SA treatment & & $0 \cdot 0125[0 \cdot 0117]$ & & [98-101] \\
\hline ART discontinuation, given no SA & & $0.0344(0.0125)[0.028]$ & & {$[98,102-105]$} \\
\hline
\end{tabular}


Table 2 (cont.)

\begin{tabular}{lllll}
\hline \hline & \multicolumn{2}{l}{ Base estimate } & \\
\cline { 2 - 3 } Variable & MSM & HM & HF & Source [ref.] \\
\hline $\begin{array}{c}\text { ART discontinuation, given SA } \\
\text { treatment } \\
\begin{array}{c}\text { Proportion achieving } \\
\text { adherence (\%) }\end{array}\end{array}$ & $0 \cdot 0182[0 \cdot 0117]$ & & {$[106]$} \\
\hline \hline
\end{tabular}

ART, Antiretroviral therapy; HAART, highly active antiretroviral therapy; HF, heterosexual female; HM, heterosexual male; MSM, men who have sex with men; NSP, needle-and-syringe exchange programme; PWID, people who inject drugs; PWUD, people who use drugs; SA, substance abuse.

* Defined as $<100 \%$ correct condom use between individual dyads.

$\dagger$ Defined as $<100 \%$ sterile syringe use with injecting partners.

+ Defined as proportion of partners from preferred sexual orientation and same drug use strata.

$\S$ Individuals who discontinue treatment at $t=j$ can re-initiate treatment at some $t>j$ with probability $p=0 \cdot 18.960 \%$ of individuals achieve $\geqslant 90 \%$ of adherence upon initiating ART (the remaining $40 \%$ are assigned to four other quartiles [0-29\%, $30-49 \%, 50-69 \%, 70-89 \%$ ] with probability $0 \cdot 10)$.

I $60 \%$ of individuals achieve $\geqslant 90 \%$ of adherence upon initiating ART [the remaining $40 \%$ are assigned to four other quartiles $(0-29 \%, 30-49 \%, 50-69 \%, 70-89 \%)$ with probability $0 \cdot 10]$.

was to determine which conceptual model structure was inherently more capable of reproducing these results, without extensive calibration procedures that may mask their limitations.

\section{Agent network, characteristics, partnership formation and model structure}

The individual 'agents' in the model are characterized by three time-varying drug-use categories [PWID, people who use non-injection drugs (PWUD), and non-drug users]. PWID agents represent individuals who have injected an illicit drug in the previous month, and PWUD represent recent users of an illicit drug (other than marijuana) through noninjection modes of consumption [109]. Agents are further stratified by sex (male, female) and sexual orientation-MSM, and heterosexual males (HM) and females (HF). Table 1 shows the population distribution specified when the individual-based model is initialized in the year 1992. During the first time step, sex, sexual orientation and drug-use status are attributed randomly to individuals to match the estimated proportion in the New York MSA in 1992, such that $6.5 \%$ are PWUD and $1.2 \%$ are PWID, of whom $7 \cdot 3 \%$ and $6 \cdot 5 \%$ are also MSM, respectively $[25,30,31]$. Among non-drug users, $2 \cdot 2 \%$ are MSM [28, 31].

In the network, given an individual $i$, the number of (sexual and/or drug using) partnerships with other individuals at time step $t$ (i.e. $k_{i, t}$ ), follows a negative binomial distribution for all individuals per time step:

$$
\begin{aligned}
& k_{i, t} \sim \mathrm{NB}(p, r)=\frac{\left(k_{i, t}+r-1\right) !}{(r-1) ! k_{i, t} !} p^{r}(1-p)^{k_{i, t}}, \\
& k_{i, t} \in \aleph_{0}, \quad i=1, \ldots, 20000, \quad t=1, \ldots, 120,
\end{aligned}
$$

where partners are acquired with probability $p$ until $r$ suitable partners are found. Negative binomial regression was used because it is appropriate for overdispersed count data $[110,111]$. This model for partnership formation and resulting partner distributions reflects empirical behaviour and data observed in previously conducted sexual and drug-using network studies (see Table 2 for sources). Partnership formation occurs when two individuals have the same sexual orientation or they are both PWID. The assortative mixing (i.e. sexual and/or needle-and-syringe (NS) sharing partnerships among people with similar risk for acquiring HIV) has been incorporated by weighting the probability of each contact to favour the formation of links between individuals with similar characteristics. For example, $90 \%$ of MSM agents who are not PWID interact exclusively with other MSM [85, 86], and the remaining $10 \%$ are linked randomly to other individuals with whom they engage in sexual intercourse. We assume that $80 \%$ of PWID have parenteral interaction only with individuals in their own subgroup [82, 83]. For PWUD, $60 \%$ are connected with other PWUD and 18\% with PWID. 
Table 3. Per-act transmission probabilities according to type of transmission, sexual orientation, and stage of HIV disease

\begin{tabular}{|c|c|c|c|c|c|}
\hline \multirow[b]{2}{*}{ Adherence level } & \multicolumn{2}{|l|}{ Sexual } & \multirow{2}{*}{$\begin{array}{l}\text { Parenteral } \\
\text { MSM/HF/HM }\end{array}$} & \multicolumn{2}{|c|}{$\begin{array}{l}\text { Monthly probability of } \\
\text { progression to AIDS }\end{array}$} \\
\hline & MSM & $\mathrm{HF} / \mathrm{HM}$ & & Non-drug users & PWID \\
\hline \multicolumn{6}{|l|}{ Acute stage } \\
\hline Not on ART & $0 \cdot 0215$ & $0 \cdot 0043$ & $0 \cdot 0301$ & $0 \cdot 00833$ & $0 \cdot 01392$ \\
\hline 0-29\% adherent to ART & $0 \cdot 0215$ & $0 \cdot 0043$ & $0 \cdot 0301$ & $0 \cdot 00833$ & $0 \cdot 01392$ \\
\hline $30-49 \%$ adherent to ART & $0 \cdot 0172$ & $0 \cdot 00344$ & $0 \cdot 02408$ & $0 \cdot 00683$ & 0.0115 \\
\hline $50-69 \%$ adherent to ART & $0 \cdot 0086$ & $0 \cdot 00172$ & $0 \cdot 01204$ & $0 \cdot 00533$ & $0 \cdot 00917$ \\
\hline $70-89 \%$ adherent to ART & $0 \cdot 0043$ & $0 \cdot 00086$ & $0 \cdot 00602$ & $0 \cdot 00383$ & $0 \cdot 00675$ \\
\hline$\geqslant 90 \%$ adherent to ART & $0 \cdot 00043$ & $0 \cdot 00009$ & $0 \cdot 0006$ & $0 \cdot 00083$ & $0 \cdot 002$ \\
\hline \multicolumn{6}{|l|}{ Latent stage } \\
\hline Not on ART & $0 \cdot 005$ & $0 \cdot 002$ & $0 \cdot 007$ & $0 \cdot 00833$ & $0 \cdot 01392$ \\
\hline $0-29 \%$ adherent to ART & $0 \cdot 005$ & $0 \cdot 002$ & $0 \cdot 007$ & $0 \cdot 00833$ & 0.01392 \\
\hline $30-49 \%$ adherent to ART & $0 \cdot 004$ & $0 \cdot 0016$ & $0 \cdot 0056$ & $0 \cdot 00683$ & $0 \cdot 0115$ \\
\hline $50-69 \%$ adherent to ART & 0.002 & $0 \cdot 0008$ & $0 \cdot 0028$ & $0 \cdot 00533$ & $0 \cdot 00917$ \\
\hline $70-89 \%$ adherent to ART & $0 \cdot 001$ & $0 \cdot 0004$ & $0 \cdot 0014$ & $0 \cdot 00383$ & 0.00675 \\
\hline$\geqslant 90 \%$ adherent to ART & $0 \cdot 0001$ & $0 \cdot 00004$ & $0 \cdot 00014$ & $0 \cdot 00083$ & $0 \cdot 002$ \\
\hline \multicolumn{6}{|l|}{ AIDS stage } \\
\hline Not on ART & $0 \cdot 0043$ & $0 \cdot 0043$ & $0 \cdot 0301$ & \multicolumn{2}{|c|}{ n.a. } \\
\hline $0-29 \%$ adherent to ART & $0 \cdot 0043$ & $0 \cdot 0043$ & $0 \cdot 0301$ & \multicolumn{2}{|c|}{ n.a. } \\
\hline $30-49 \%$ adherent to ART & $0 \cdot 00344$ & $0 \cdot 00344$ & $0 \cdot 02408$ & \multicolumn{2}{|c|}{ n.a. } \\
\hline $50-69 \%$ adherent to ART & 0.00172 & $0 \cdot 00172$ & $0 \cdot 01204$ & \multicolumn{2}{|c|}{ n.a. } \\
\hline $70-89 \%$ adherent to ART & 0.00086 & $0 \cdot 00086$ & $0 \cdot 00602$ & \multicolumn{2}{|c|}{ n.a. } \\
\hline$\geqslant 90 \%$ adherent to ART & $0 \cdot 00009$ & $0 \cdot 00009$ & $0 \cdot 0006$ & \multicolumn{2}{|c|}{ n.a. } \\
\hline
\end{tabular}

ART, Antiretroviral therapy; HF, heterosexual female; HM, heterosexual male; PWID, people who inject drugs; MSM, men who have sex with men, n.a., not applicable.

More details about the assortative mixing are presented in Table 2.

In order to avoid overestimation of the sexual and/ or NS sharing partnership turnover or underestimation of the partnership duration that may result from randomly re-assigning all links at each new time step, we developed the following algorithm that describes the process of partnership formation and dissolution. First, the number of target partners is randomly generated for each individual based on the negative binomial distributions described in equation (1), based on agent type (i.e. MSM, PWID). Second, agents whose partner numbers has decreased at the beginning of new month lose partnerships stochastically until the new partner number is reached. This process represents partnership dissolution (i.e. 'break-ups'). Third, agents whose partner numbers increased at the beginning of new month are assigned new partners from the available pool of agents. This process proceeds iteratively through the agent population until all agents receive the targeted number of partners. Note that partnerships are also dissolved as a result of the death of one member of the pair. As the simulation proceeds, the number of partners for each agent varies; thus, both concurrent and sequential partnerships are possible.

In primary analyses, the model consisted of a population of $N=20000$ agents run over 120 monthly time steps (representing 10 years, 1992-2002). The model assumes that the characteristics (e.g. drug use, HIV disease stage) of each individual $i, i=1, \ldots, 20000$ is updated on a discrete and monthly time step $t$, $t=1, \ldots, 120$, following pre-programmed rules and interactions with other individuals, $1, \ldots, i-1, i+$ $1, \ldots, 20000$.

During the simulation HIV-uninfected agents can acquire HIV through unprotected sexual intercourse and/or NS sharing with HIV-infected agents. We defined unprotected intercourse between two agents as $<100 \%$ correct and consistent condom use. Once infected, the natural history of HIV infection was modelled by considering three disease stages $d$ [acute stage (AS), latent stage (LS), and AIDS], $d=\mathrm{AS}, \mathrm{LS}$, AIDS. Acute HIV infection is defined as the period immediately after infection during which the initial viraemia (and high infectiousness) occurs. On average, 
acute infection is considered to last 3 months following HIV acquisition [112, 113]; thus, we considered the first three time steps following infection as the acute phase.

At each time step, HIV-infected agents have a prespecified probability of 'accessing' HIV testing; following which ART can be initiated (after 1996). Once an HIV-positive agent is assigned ART, the model randomly assigns one of the six adherence levels of ART $(j, j=0, \ldots, 5)$, which varies between $0 \%$ and $100 \%$, such that $60 \%$ of individuals achieve $\geqslant 90 \%$ adherence [107]. These adherence levels correspond to a viral load $\left(\log _{10}\right.$ copies $\left./ \mathrm{ml}\right)$ that decreases from $4 \cdot 5$ to $0 \cdot 5$.

\section{HIV transmission probability models}

HIV transmission within serodiscordant partnerships (i.e. dyads) is determined by the per-partner transmission probability, $\beta_{p}^{i, j, d, t}$, which depends on per-act transmission probability, $\beta_{a}^{i, j, d, t}$, and the number of unprotected sex, $n_{\text {unp }}^{i, t}$, and/or syringe-sharing acts, $n_{\mathrm{NS}}^{i, t}$, within a partnership for each individual $i(i=1, \ldots$, $20000)$, for every $j(j=0, \ldots, 5)$ adherence levels, in disease stages $d$ ( $d=\mathrm{AS}, \mathrm{LS}$, AIDS), at time step $t$ $(t=1, \ldots, 120)$. We assume that the per-partnership transmission probability follows a Binomial distribution [1], where transmission is sexual or parenteral, respectively in equations (2) and (3):

$$
\begin{aligned}
\beta_{p, \text { unp }}^{i, j, d, t} & \sim \operatorname{Bin}\left(1, n_{\text {unp }}^{i, t}, \beta_{a, \text { unp }}^{i, j, d, t}\right) \\
& =\beta_{a, \text { unp }}^{i, j, d, t}\left(1-\beta_{a, \text { unp }}^{i, j, t}\right)^{1-n_{\text {unp }}^{i, t}}, \\
\beta_{p, \mathrm{NS}}^{i, j, d, t} & \sim \operatorname{Bin}\left(1, n_{\mathrm{NS}}^{i, t}, \beta_{a, \mathrm{NS}}^{i, j, d, t}\right) \\
& =\beta_{a, \mathrm{NS}}^{i, j, d, t}\left(1-\beta_{a, \mathrm{NS}}^{i, j, d, t}\right)^{1-n_{\mathrm{NS}}^{i, t}} .
\end{aligned}
$$

We constructed and analysed four HIV transmission models, each based on the previous iteration but incorporating more heterogeneity as described below.

\section{Model 1: constant model}

The simplest model assumed that the per-partnership transmission probability varies by ART adherence (for agents assigned ART) and HIV disease stage, but does not depend on the number of unprotected sex and the NS sharing acts, which are considered to be constant across all partnerships per time step. Although agent-based models of HIV transmission typically incorporate behavioural differences in engagement in risk behaviour at the individual level, we assess this model structure, as it is similar in concept to some deterministic models that have evaluated the preventive benefits of ART [114]. The per-act transmission probability is equal to $c^{j, d}$, varying by ART adherence and HIV disease stage:

$n_{\text {unp }}^{i, t}=n_{\text {unp }}$ and $\beta_{a}^{i, j, d, t}=\beta_{a}^{j, d}=c_{\text {unp }}^{j, d}, \quad j=0, \ldots, 5$;

$d=\mathrm{AS}, \mathrm{LS}$, AIDS [sexual transmission].

$n_{\mathrm{NS}}^{i, t}=n_{\mathrm{NS}}$ and $\beta_{a}^{i, j, d, t}=\beta_{a}^{j, d}=c_{\mathrm{NS}}^{j, d}, \quad j=0, \ldots, 5 ;$

$d=\mathrm{AS}, \mathrm{LS}, \mathrm{AIDS}$ [parenteral transmission].

Thus, depending on the type of HIV transmission, the per-partnership transmission probability is given by:

$$
\begin{aligned}
\beta_{p}^{i, j, d, t} & =c_{\mathrm{unp}}^{j, d}\left(1-c_{\mathrm{unp}}^{j, d}\right)^{n_{\mathrm{unp}}-1}, \quad j=0, \ldots, 5 ; \\
d & =\mathrm{AS}, \mathrm{LS}, \text { AIDS [sexual transmission]. } \\
\beta_{p}^{i, j, d, t} & =c_{\mathrm{NS}}^{j, d}\left(1-c_{\mathrm{NS}}^{j, d}\right)^{n_{\mathrm{NS}}-1}, \quad j=0, \ldots, 5 ; \\
d & =\mathrm{AS}, \text { LS, AIDS [parenteral transmission]. }
\end{aligned}
$$

Table 3 shows the values for the per-act transmission probabilities for syringe-sharing events [13, 115, 116] and unprotected sex acts [116-121]. Also shown are the monthly transition probabilities for progressing to AIDS [66, 122, 123].

\section{Model 2: random number of acts}

Previous studies have shown differences in condom usage by serostatus and by partners of PWID, and should thus be incorporated into HIV epidemic models [76]. The second model is more complicated by introducing stochasticity to the number of unprotected sex [equation (4)] and the NS sharing [equation (5)] acts. This model structure has been used to evaluate HIV prevention services (including NS programmes) for people who inject drugs [124, 125]. Specifically, these values are assigned within a partnership for each individual and from Poisson distributions [126]:

$n_{\text {unp }}^{i, t} \sim \operatorname{Poi}\left(\lambda_{\text {unp }}\right)=\frac{\lambda_{\text {unp }}^{i_{\text {unp }}^{i, t}} \mathrm{e}^{-\lambda_{\text {unp }}}}{n_{\text {unp }}^{i, t} !}, \quad n_{\text {unp }}^{i, t} \geqslant 0 ;$

$i=1, \ldots, N ; \quad t=1, \ldots, 120$,

$\frac{n_{\mathrm{NS}}^{i, t} \sim \operatorname{Poi}\left(\lambda_{\mathrm{NS}}\right)=\lambda_{\mathrm{NS}}^{i_{\mathrm{NS}}^{i, t}} \mathrm{e}_{\mathrm{NS}}^{-\lambda}}{n_{\mathrm{NS}}^{i, t} !}, \quad n_{\mathrm{NS}}^{i, t} \geqslant 0 ;$ 
As in model 1, the per-partnership transmission probabilities also vary by partnership and time, and depend on highly active ART adherence levels (for agents on ART) and HIV disease stage.

\section{Model 3: individual viral load}

In the third model, we varied the per-act transmission probability by individual plasma HIV RNA viral load. We used each HIV-infected agent's viral load (stochastically assigned as described below) to calculate unique per-act risks of HIV transmission for each serodiscordant dyad.

Fraser et al. [127] found significant heterogeneity in asymptomatic (or set-point) viral load, which varies between and within the stages of the disease. Previous cross-sectional surveys have also shown that, during untreated latent stage, HIV viral load varies between 4 and $5 \log _{10}$ copies/ml [128-130]. Therefore, in model 3, we assumed a viral load of $4.5 \log _{10}$ copies $/ \mathrm{ml}$ as the baseline, and assigned a viral load equal to 0 or $4.5 \log _{10}$ copies $/ \mathrm{ml}$ to all the individuals before year 1996. It is also known that immediately after exposure and transmission, the viral load is undetectable in plasma and this generally lasts 7-21 days [131, 132]. Thus, when an individual becomes HIV infected, the adherence levels correspond to a $\log _{10}$ viral load copies/ml that decreases from 4.5 to 0.0 during the first month. In the following 2 months the individual will be allocated a $\log _{10}$ viral load between 6.9 and 0.5 copies $/ \mathrm{ml}$. During the acute and AIDS stage all agents were assumed to have 7.0 $\log _{10}$ viral load copies/ml [14, 113, 133].

Each individual's per-act risk of HIV transmission was calculated based on results of a study by Baggaley et al. [119], in which the relationship between probability of HIV transmission and plasma HIV RNA viral load (copies/ml) was determined. The vaginal per-act probability of HIV transmission, $\beta_{\mathrm{a}, \mathrm{vag}}^{i}$, was best estimated as a function of an individual's viral load as follows:

$$
\begin{aligned}
& \beta_{\mathrm{a}, \mathrm{vag}}^{i, j, t}=1-\left(1-\frac{0 \cdot 317\left(\mathrm{VL}^{i, j, d, t}\right)^{1.02}}{\left(\mathrm{VL}^{i, j, d, t}\right)^{1.02}+13938^{1 \cdot 02}}\right)^{\frac{1}{8317544}}, \\
& i=1, \ldots, 20000 ; j=0, \ldots, 5 ; d=\mathrm{AS}, \mathrm{LS}, \text { AIDS; } \\
& t=1, \ldots, 120,
\end{aligned}
$$

and the corresponding anal and parenteral HIV peract probability, $\beta_{\mathrm{a}, \text { anal }}^{i, j, d}$ and $\beta_{\mathrm{a}, \text { inj }}^{i, j, t}$, are respectively given by:

$\beta_{\mathrm{a}, \text { inj }}^{i, j, t}=4.67 \times \beta_{\mathrm{a}, \mathrm{vag}}^{i, j, d, t}, \quad i=1, \ldots, 20000 ;$

$j=0, \ldots, 5 ; d=\mathrm{AS}, \mathrm{LS}, \mathrm{AIDS} ; t=1, \ldots, 120$,

$\beta_{\mathrm{a}, \text { anal }}^{i, j, d, t}=3.50 \times \beta_{\mathrm{a}, \mathrm{vag}}^{i, j, d, t}, \quad i=1, \ldots, 20000 ;$

$j=0, \ldots, 5 ; d=\mathrm{AS}, \mathrm{LS}, \mathrm{AIDS} ; t=1, \ldots, 120$,

where 4.67 and 3.50 represent the estimated increase in per-act risk of HIV transmission for parenteral and anal intercourse compared to vaginal intercourse, respectively $[119,134]$.

\section{Model 4: two groups}

Previous studies have suggested that observed heterogeneity in HIV transmission rates may be partially explained by differential risk behaviour across different types of partnerships. Earlier work has generally divided partnership types into two groups (i.e. regular partner, primary, and non-regular partners, casual) [5, 135]. In general, condom use is more frequent with casual partners than with a steady partner [136-138]. Similar discrepancies have also been observed between steady and non-regular partners for NS sharing (i.e. higher sharing rates with primary partners) $[55,139,140]$.

Thus, the fourth and most complex model builds on the third, but considers two groups of partnerships, with either a higher (primary partner), ${ }^{\text {primary }} n_{\text {unp }}^{i, t}$ and ${ }^{\text {primary }} n_{\mathrm{NS}}^{i, t}$, or lower [casual partner(s)], ${ }^{\text {casual }} n_{\text {unp }}^{i, t}$ and casual $n_{\mathrm{NS}}^{i, t}$, number of unprotected sex and NS sharing acts, respectively. Stratifying the population into 'low' and 'high' risk groups is a common feature of previously published HIV transmission models [5, 55, 135-140].

\section{Model outcomes and sensitivity analyses}

The individual-based model was coded in Python ${ }^{\mathrm{TM}}$ version 2.7.2, an open-source programming language [141], and the simulations conducted on a supercomputer at the Brown University Center for Computation and Visualization. The simulation was conducted using Monte Carlo methods to account for uncertainty in model outputs arising from the many processes and behaviours that are stochastic, by repeating each scenario 100 times. Mean estimates and 95\% confidence intervals (CIs) for annual HIV incidence in the populations of non-drug users and PWID (and other outputs of interest) were obtained for each HIV transmission model. We then compared the trends of HIV prevalence and annualized incidence among 

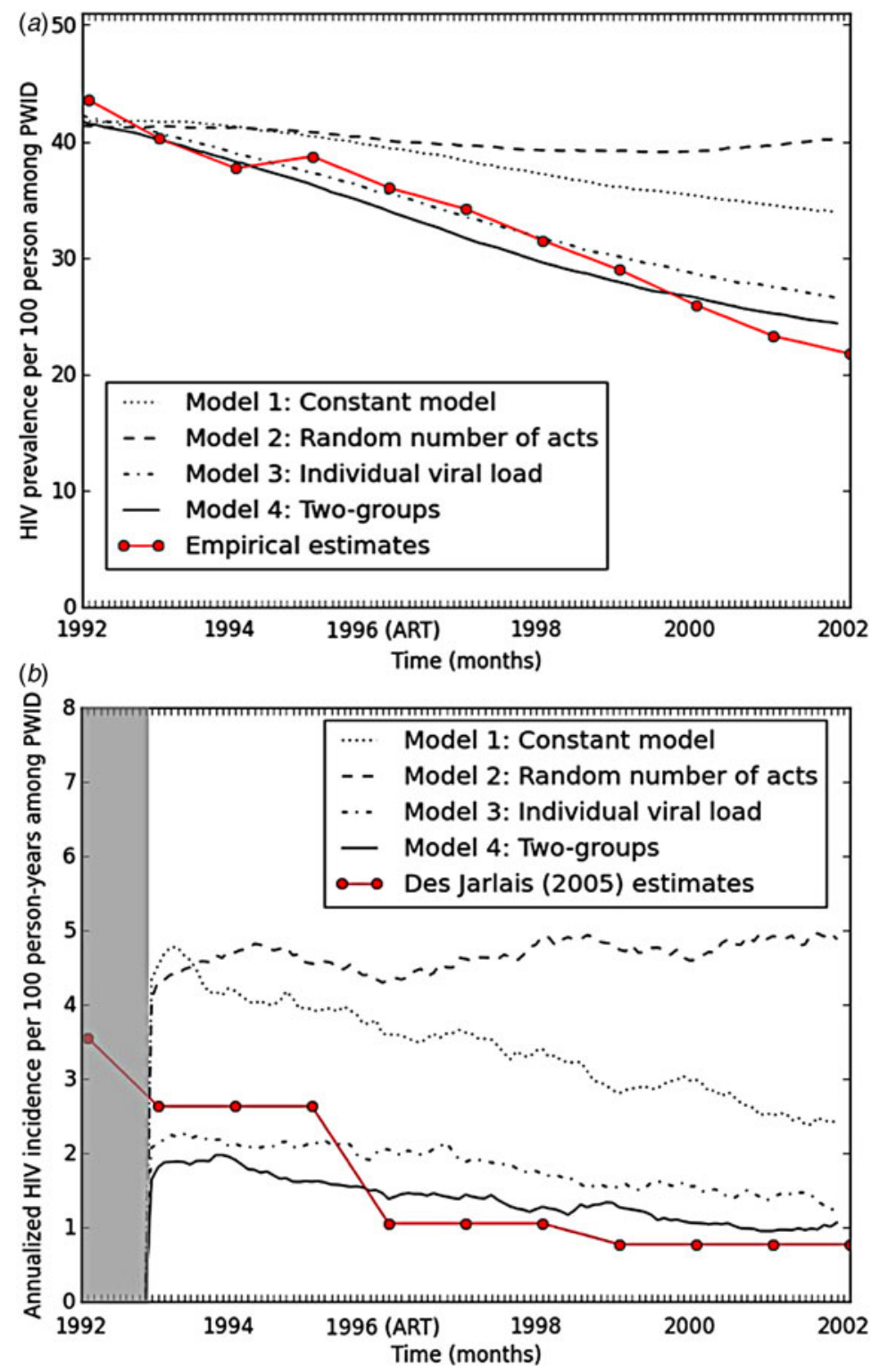

Fig. 1. (a) Estimated HIV prevalence and (b) annualized incidence in people who inject drugs (PWID) in New York, from 1992 to 2002, obtained from a Monte Carlo simulation of an individual-based model, considering four models for HIV transmission probability. In each panel, four HIV transmission probability models for sexual and parenteral transmission are presented: model 1, constant probabilities; model 2, random number of sexual and parenteral acts; model 3, viral load is individual assigned; model 4, two groups of partnerships (low and high risk). Red, dotted line indicates the empirical estimates of HIV (a) prevalence [27], and (b) incidence [142] observed in New York in PWID, from 1992 to 2002. In panel $(b)$ the grey area represents the 'burn-in' period, since HIV incidence was annualized, and there are no estimated data before 1993. ART, Antiretroviral therapy.

PWID (per 100 persons), comparing models $1-4$ to the empirical estimates for HIV prevalence [27], and incidence [142], observed in New York among PWID, from 1992 to 2002. Percent relative bias between model estimates and the HIV incidence rates observed empirically were calculated, and Pearson's $\chi^{2}$ test statistic [143] was used as a measurement of goodness of fit to determine which model produced more satisfactory estimates. A lower value of Pearson's $\chi^{2}$ test statistic indicates a better fit of the model to the observed data. As a secondary analysis, we also investigated the number of NS sharing acts per month outputted from the four different HIV transmission models.

Sensitivity analyses were performed to describe the extent to which changing the HIV transmission models and their respective parameter values affected the 

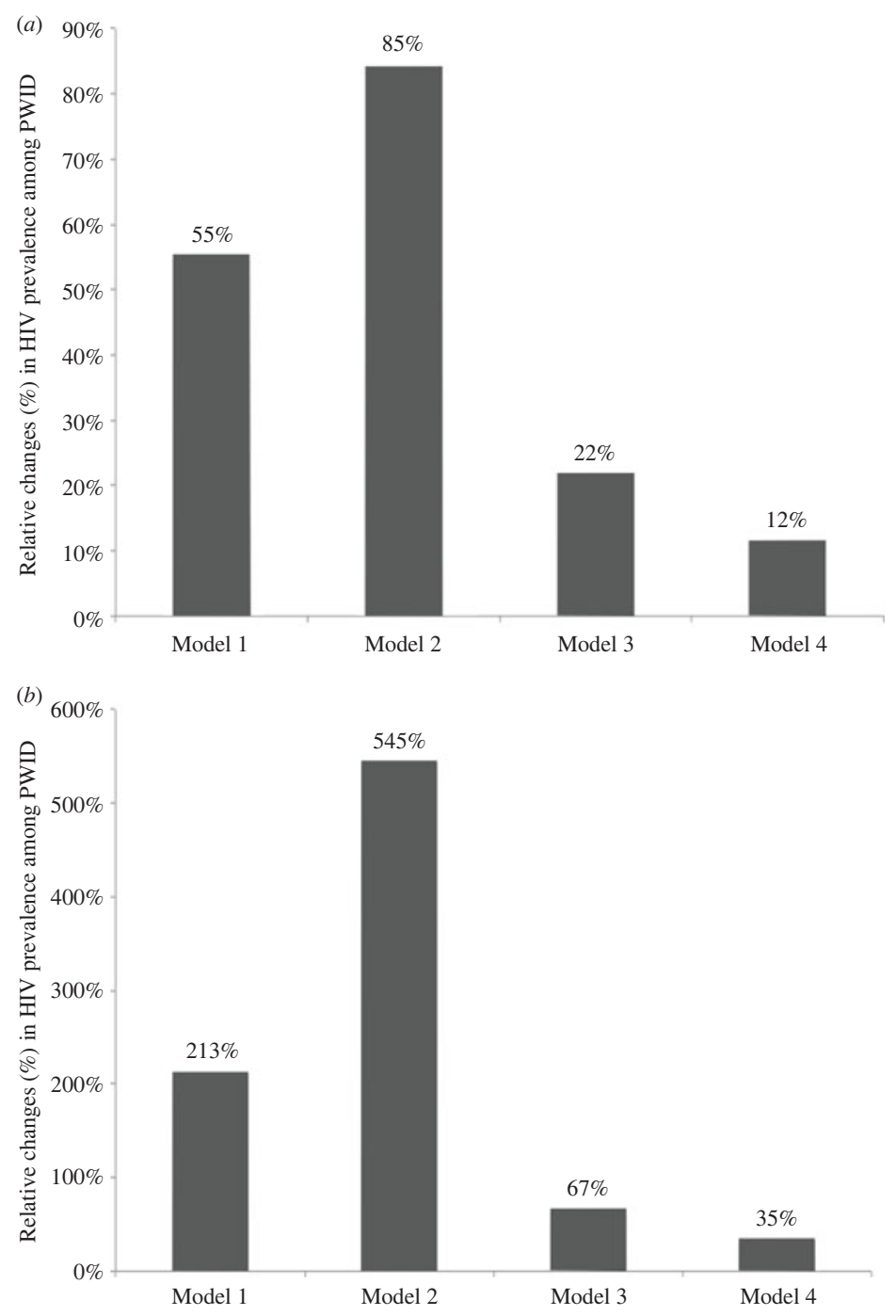

Fig. 2. Relative bias in (a) HIV prevalence and $(b)$ annualized HIV incidence in people who inject drugs (PWID) in New York, in 2002, obtained from a Monte Carlo simulation of the individual-based model, considering four models for HIV transmission probability. In each panel are represented estimates considering four HIV transmission probability models for sexual and parenteral infections: model 1, constant probabilities; model 2, random number of sexual and parenteral acts; model 3, viral load is individual assigned; model 4, two groups of partnerships (low and high risk). The percentage relative biases were calculated relative to the observed HIV prevalence and incidence observed in 2002, respectively to panel $(a)$ and $(b)$ HIV prevalence [27, 142].

primary results. For each model (models $1-4)$, we considered five scenarios for the number of unprotected sex acts and syringe-sharing, respectively, and the peract transmission probabilities, where the reference values were increased by $25 \%$ and $50 \%$, and decreased by $25 \%$ and $50 \%$, separately and then simultaneously.

\section{RESULTS}

\section{Trends in HIV infections in PWID}

Table 2 presents the values for monthly risk behaviour probabilities [28, 36, 38-46], NS sharing acts, and other model parameters (sources provided in table). In Figure 1, we show the trends in HIV prevalence and incidence obtained from each model, in addition to the empirical estimates. The most basic model (model 1, in which per-act transmission probabilities and numbers of unprotected sex and NS shared acts were constant), did not approximate the observed incidence and prevalence among PWID between 1992 and 2002, with Pearson's $\chi^{2}$ test statistic equal to $0 \cdot 1248$ and $0 \cdot 1412$, respectively. We were also unable to reproduce observed HIV epidemic trajectories when stochasticity was incorporated in the number 

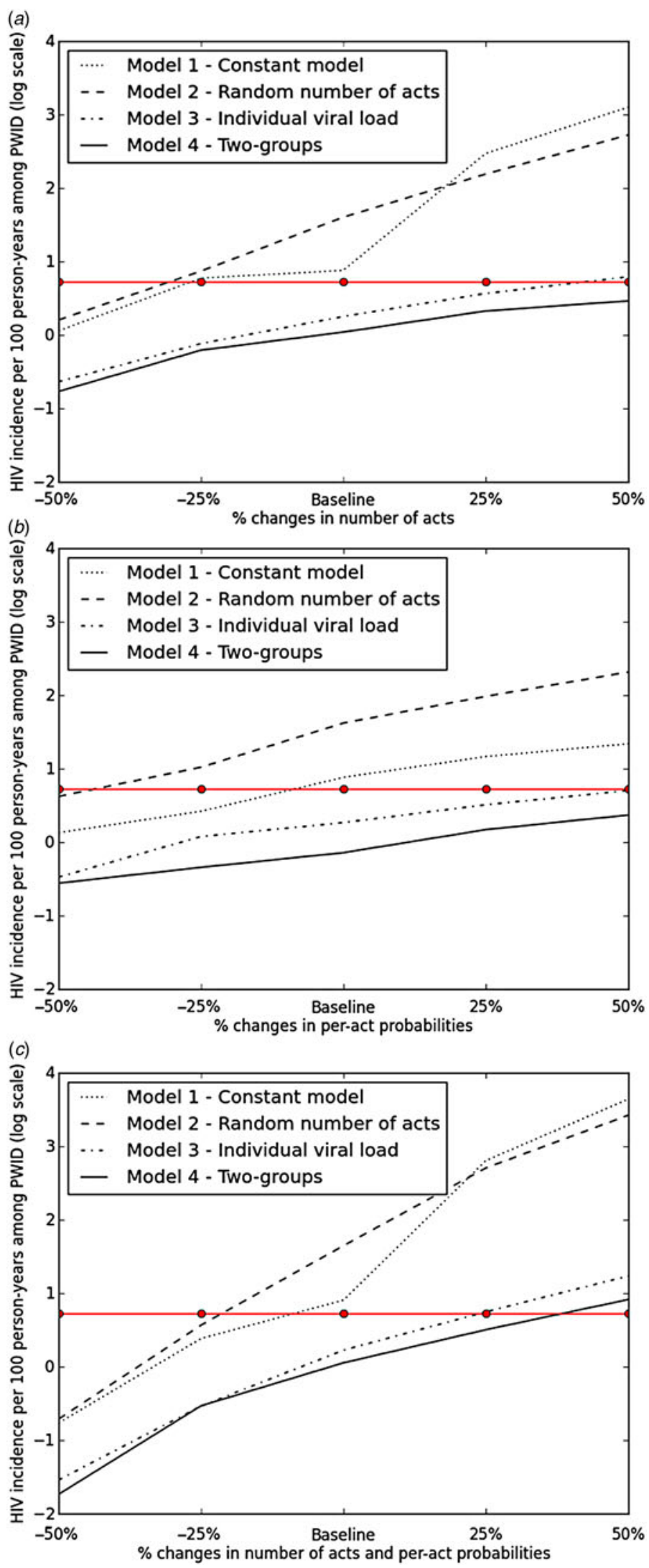

Fig. 3. Projected HIV incidence (per 100 person-years) in 2002 in people who inject drugs (PWID) in New York, considering four models for HIV transmission probabilities, for three different sensitivity analyses: $(a)$ changes in number of risk acts, $(b)$ per-act transmission probability, and $(c)$ number of acts and per-act probabilities. In $(a-c)$ for each HIV 
of sexual and parenteral acts (model 2), resulting in the worst fit to the data compared to other models (i.e. the Pearson's $\chi^{2}$ test statistic was $0 \cdot 2401$ and $0 \cdot 2559$, respectively for HIV incidence and prevalence). Both models substantially overestimated HIV prevalence and incidence, particularly in later years of the simulation. In contrast, models 3 and 4, in which agents were assigned individual viral load values and also engaged in two types of partnerships, respectively, better re-produced HIV prevalence and incidence trends that were observed historically in PWID. For model 3 we obtained the following Pearson's $\chi^{2}$ test statistic: $0 \cdot 0281$ and $0 \cdot 0203$, respectively, for HIV incidence and prevalence. Model 4 presented better fit to the HIV incidence and prevalence in PWID, with Pearson's $\chi^{2}$ test statistic equal 0.0209 and $0 \cdot 0107$, respectively.

The projected HIV prevalence in 2002 in the New York MSA was estimated to be $34 \%$ (95\% CI $25-42$ ), $40 \%$ (95\% CI 32-49), 27\% (95\% CI 19-34), and $24 \%$ (95\% CI 18-31) in PWID in models $1-4$, respectively. HIV incidence in 2002 was estimated to be $2 \cdot 4$ (95\% CI $0 \cdot 0-5 \cdot 0), 5 \cdot 0$ (95\% CI $1 \cdot 1-8 \cdot 8), 1 \cdot 3(95 \%$ CI $0 \cdot 0-3 \cdot 0)$, and $1 \cdot 0(95 \%$ CI $0 \cdot 0-2 \cdot 7)$ per 100 personyears in models 1-4, respectively. In Figure 2, we show the relative bias in projected HIV incidence in 2002 compared to that which was actually observed in New York PWID [142]. Although all models overestimated HIV prevalence by the end of the simulation, the relative bias was smallest in model 4. Similar patterns were observed for relative bias of estimated HIV incidence in 2002 (Fig. 2b). Once again, all models overestimated HIV incidence, but the relative bias was smallest in models 3 and 4.

\section{Sensitivity analyses}

In a series of sensitivity analyses (see Fig. 3), our simulation showed that the constant probabilities and random number of acts models were highly sensitive to changes in the number of sexual and/or parenteral acts per time step, in non-drug users and PWID, respectively. In scenarios where the number of sexual and/or parenteral acts were scaled up 25\% and 50\% (compared to those used in the primary analyses), unrealistically high HIV incidence rates in 2002 were projected in PWID: $11 \cdot 8 \%(95 \%$ CI 5.2-18.5) and $22 \cdot 2 \%(95 \%$ CI $12 \cdot 6-31 \cdot 8 \%)$ per 100 person-years in the constant probabilities model, and $8.9 \%$ (95\% CI $3 \cdot 3-14 \cdot 6)$ and $15 \cdot 2 \%(95 \%$ CI $6 \cdot 3-24 \cdot 2)$ per 100 person-years in the random number of acts model, respectively. HIV transmission models with individual viral load and the two-group partnership model were significantly less sensitive to changes in number of sexual and/or parenteral acts, with the individual-based model producing acceptable output (compared to the highest incidence observed in New York in PWID, from 1992 to 2002) [142] HIV incidence estimates in 2002 among PWID across all sensitivity analysis scenarios (see Fig. 3a). Similar results were obtained when per-act transmission probabilities were increased (Fig. 3b), and then number of monthly risk acts and per-act transmission probabilities were scaled up simultaneously (Fig. 3c).

\section{DISCUSSION}

In this simulation study, we found that HIV transmission models with less heterogeneity were unable to reproduce HIV epidemic trajectories observed historically in PWID, and were highly sensitive to changes in key parameters (e.g. number of risk acts within serodiscordant partnerships). In contrast, models which incorporated more heterogeneity - for example, transmission dependent on individually assigned viral loads - produced satisfactory estimates of HIV prevalence and incidence, and showed less sensitivity to changes in key parameters. Our results support the work of previous mathematical modelling studies that have demonstrated the need for representing heterogeneity in behaviour and determinants of transmission probabilities to appropriately capture HIV transmission dynamics in non-drug using populations [144-146]. Furthermore, our study could serve as an important guideline for critical model structures and processes that should be included in future

transmission probability model (1-4), we considered four scenarios for the number of unprotected sex acts and needle and syringe sharing, respectively, and the per-act transmission probabilities, where the baseline parameter values are increased by $25 \%$ and $50 \%$, and decreased by $25 \%$ and $50 \%$. In each panel, four HIV transmission probability models are presented: model 1, constant probabilities; model 2, random number of sexual and parenteral acts; model 3, viral load is individual assigned; model 4, two groups of partnerships (low and high risk). Red-dotted line indicates the highest HIV incidence (in log scale) observed in New York in PWID, from 1992 to 2002, as estimated in Des Jarlais et al. [142]. 
individual-based models of HIV transmission in dynamic networks.

The HIV transmission model that considered two types of partnerships (primary and casual) was able to better reproduce observed HIV prevalence and incidence trajectories than a model without partner-level differences in risk behaviour rates. This finding supports the work of Kretzschmar \& Wiessing [147] who demonstrated that reducing rates of NS sharing with strangers is more effective than reducing the overall sharing frequency to decrease HIV transmission at the population level.

Some limitations to this simulation study should be noted. First, the modelled population size (20000) was relatively small, and larger simulations are recommended to confirm our findings. However, we do not expect simulations with a larger population size to result in substantially different findings, given that we were able to qualitatively reproduce the HIV epidemic trajectories observed historically. Moreover, we parameterized the model with detailed data regarding risk behaviours among non-drug users, PWID, and PWUD (further stratified by sex and sexual orientation), which represents the MSA of New York. Finally, comparisons of the output from the various model structures were not limited by lack of precision in the primary estimates of interest (i.e. HIV incidence and prevalence in 2002). Second, although the effect of interventions such as provision of ART, NS programmes, and opioid substitution therapy were coded in the model, we did not incorporate other behavioural and structural interventions (e.g. serosorting). Furthermore, as our model sought to reproduce historical HIV epidemic trajectories, we did not incorporate interventions such as pre-exposure prophylaxis (PrEP) or post-exposure prophylaxis (PEP). Given the potential for PrEP and PEP to reduce the acquisition of HIV infection in MSM and PWID [148, 149], future research should be conducted to take into account the impact of these interventions in this setting. Third, although we did increase HIV transmission risk during the 3 months following infection, more sophisticated models are needed to understand the effect of varying durations of the acute infection phase in HIV transmission models. Fourth, further investigation is needed to lead to a better understanding why incidence and prevalence are overestimated by all four models. Friedman et al. [150] suggested that, in stable high-prevalence epidemic contexts, the relatively small size of sub-networks of linked seronegatives may limit infectious outbreaks.
This process, known as the 'firewall effect' $[150,151]$, captures an important barrier to HIV propagation in PWID risk networks. Future work will investigate whether this effect is observed in the simulated network of PWID in our model. Fifth, a recent study indicated that current estimates of HIV-1 acute-phase infectivity relative to chronic infection may be substantially overestimated [152]. Future work will be conducted to determine whether reducing the relative acute-phase infectivity results in improved model fit to HIV incidence and prevalence trends. We note, however, that the effect of changing the relative infectivity in acute phase would not influence which model performed best, and consequently the interpretation of our current results. Sixth, our model did not incorporate more complex behavioural processes including mixing within and across age groups, age of sexual/injection debut, changing sexual/injection behaviour with age or time, and the effect of migration, given that there is not enough data to parameterize the model processes for some of these behavioural complexities. Future work will improve the individualbased model, with the goal of better understanding the HIV transmission dynamic process. Finally, as in all mathematical models, parameter values are subject to error. We conducted Monte Carlo simulations and sensitivity analyses to assess the degree to which uncertainty in parameter estimates affected our results, but nonetheless our findings should be interpreted within the context of this important limitation.

\section{CONCLUSIONS}

Overall, HIV transmission models with less heterogeneity were more sensitive to changes in numbers of sexual and parenteral acts, producing HIV incidence rates up to four times higher than those empirically observed. Although all models overestimated HIV prevalence and incidence, microsimulations with greater heterogeneity in the HIV transmission process, specifically transmission determined by individual viral loads, produced more robust results and better reproduced empirical epidemic dynamics among PWID in New York from 1992 to 2002.

\section{ACKNOWLEDGEMENTS}

The authors thank the staff and resources provided by the Brown University Center for Computation \& Visualization. The authors also acknowledge Dr 
Magdalena Paczkowski for assisting with the individual-based model Python code.

This research was supported, in part, by a T32 training grant from the National Institute on Drug Abuse awarded to The Miriam Hospital (T32-DA13911). This project is funded in part by the National Institutes of Health (R01-DA013336) as part of the Community Vulnerability and Responses to Drug-User Related HIV/AIDS (CVAR) study, and was also funded in part by a developmental grant from the Lifespan/Tufts/Brown Center for AIDS Research (P30-AI042853). Dr Filipe Monteiro is supported by a postdoctoral fellowship, T32 Training Programme in HIV and Other Consequences of Substance Abuse (grant no. T32-DA013911). Dr Brandon Marshall was supported by a Salomon Faculty Research Award from Brown University. Daniel Escudero was supported by the National Institutes of Health/National Institute on Drug Abuse (F31-DA037808).

\section{DECLARATION OF INTEREST}

None.

\section{REFERENCES}

1. Kaplan EH. Modeling HIV infectivity: must sex acts be counted? Journal of Acquired Immune Deficiency Syndromes 1990; 3: 55-61.

2. Greenhalgh D, Lewis F. The general mixing of addicts and needles in a variable-infectivity needle-sharing environment. Journal of Mathematical Biology 2002; 44: 561-598.

3. Blower SM, Boe C. Sex acts, sex partners, and sex budgets: implications for risk factor analysis and estimation of HIV transmission probabilities. Journal of Acquired Immune Deficiency Syndromes 1993; 6: 1347-1352.

4. Garnett GP, Anderson RM. Strategies for limiting the spread of HIV in developing countries: Conclusions based on studies of the transmission dynamics of the virus. Journal of Acquired Immune Deficiency Syndromes and Human Retrovirology 1995; 9: 500-513.

5. Jewell NP, Shiboski SC. Statistical analysis of HIV infectivity based on partner studies. Biometrics 1990; 46: 1133-1150.

6. Røttingen J-A, Garnett GP. The epidemiological and control implications of HIV transmission probabilities within partnerships. Sexually Transmitted Diseases 2002; 29: 818-827.

7. May RM, Anderson RM. The transmission dynamics of human immunodeficiency virus (HIV). Philosophical Transactions of the Royal Society of London, Series B, Biological sciences 1988; 321: 565-607.
8. Dosekun O, Fox J. An overview of the relative risks of different sexual behaviours on HIV transmission. Current opinion in HIV and AIDS 2010; 5: 291-297.

9. Scott HM, et al. Age, race/ethnicity, and behavioral risk factors associated with per contact risk of HIV infection among men who have sex with men in the united states. Journal of Acquired Immune Deficiency Syndromes 2014; 65: 115-121.

10. Centers for Disease Control and Prevention (CDC). Estimated percentages and characteristics of men who have sex with men and use injection drugs - United States, 1999-2011. Morbidity and Mortality Weekly Report 2013; 62: 757-762.

11. Kapadia F, et al. The relationship between non-injection drug use behaviors on progression to aids and death in a cohort of HIV seropositive women in the era of highly active antiretroviral therapy use. Addiction 2005; 100: 990-1002.

12. Wiley JA, Herschkorn SJ, Padian NS. Heterogeneity in the probability of HIV transmission per sexual contact: the case of male-to-female transmission in penile-vaginal intercourse. Statistics in Medicine 1989; 8: 93-102.

13. Baggaley RF, et al. Risk of HIV-1 transmission for parenteral exposure and blood transfusion: a systematic review and meta-analysis. AIDS 2006; 20: 805-812.

14. Fraser $\mathbf{C}$, et al. Variation in HIV-1 set-point viral load: epidemiological analysis and an evolutionary hypothesis. Proceedings of the National Academy of Sciences USA 2007; 104: 17441-17446.

15. Blaser $\mathbf{N}$, et al. Impact of viral load and the duration of primary infection on HIV transmission: systematic review and meta-analysis. AIDS 2014; 28: 1021-1029.

16. Auchincloss AH, Diez Roux AV. A new tool for epidemiology: the usefulness of dynamic-agent models in understanding place effects on health. American Journal of Epidemiology 2008; 168: 1-8.

17. Monteiro JF, et al. Evaluating HIV prevention strategies for populations in key affected groups: the example of cabo verde. International Journal of Public Health. Published online: 4 April 2015. doi: 10.1007/ s00038-015-0676-9.

18. Marshall BD, et al. Prevention and treatment produced large decreases in HIV incidence in a model of people who inject drugs. Health Affairs 2014; 33: 401-409.

19. Maglio PP, Mabry PL. Agent-based models and systems science approaches to public health. American Journal of Preventive Medicine 2011; 40: 392-394.

20. Marshall BD, et al. A complex systems approach to evaluate HIV prevention in metropolitan areas: preliminary implications for combination intervention strategies. PLoS One 2012; 7: e44833.

21. Gorman DM, et al. Agent-based modeling of drinking behavior: a preliminary model and potential applications to theory and practice. American Journal of Public Health 2006; 96: 2055-2060.

22. Marshall BD, Galea S. Formalizing the role of agentbased modeling in causal inference and epidemiology. American Journal of Epidemiology 2015; 181: 92-99.

23. Abuelezam NN, Rough K, Seage 3rd GR. Individualbased simulation models of HIV transmission: reporting 
quality and recommendations. PLoS ONE 2013; 8: e75624.

24. Brady JE, et al. Estimating the prevalence of injection drug users in the U.S. And in large U.S. Metropolitan areas from 1992 to 2002. Journal of Urban Health 2008; 85: 323-351.

25. Lieb S, et al. Statewide estimation of racial/ethnic populations of men who have sex with men in the U.S. Public Health Report 2011; 126: 60-72.

26. Lieb S, et al. An HIV prevalence-based model for estimating urban risk populations of injection drug users and men who have sex with men. Journal of Urban Health 2004; 81: 401-415.

27. Tempalski B, et al. HIV prevalence rates among injection drug users in 96 large us metropolitan areas, 1992-2002. Journal of Urban Health 2009; 86: 132-154.

28. Absalon J, et al. Gender differences in sexual behaviors, sexual partnerships, and HIV among drug users in new york city. AIDS and Behavior 2006; 10: 707-715.

29. Des Jarlais DC, et al. HIV infection during limited versus combined HIV prevention programs for idus in new york city: the importance of transmission behaviors. Drug and Alcohol Dependence 2010; 109: 154-160.

30. Xu F, Sternberg MR, Markowitz LE. Men who have sex with men in the united states: Demographic and behavioral characteristics and prevalence of HIV and HSV-2 infection: results from national health and nutrition examination survey 2001-2006. Sexually Transmitted Diseases 2010; 37: 399-405.

31. SAMHSA. National prevalence estimates for top 20 metropolitan statistical areas (MSAs). Office of Applied Studies, U.S. Department of Health and Human Service (http://oas.samhsa.gov/2k5States/ metro2k5PE.doc). 2010.

32. Warner LA, et al. Prevalence and correlates of drug use and dependence in the United States. Results from the national comorbidity survey. Archives of General Psychiatry 1995; 52: 219-229.

33. Marshall BDL, et al. Elevated syringe borrowing among men who have sex with men: a prospective study. Journal of Acquired Immune Deficiency Syndromes 2007; 46: 248-252.

34. Miller M, Neaigus A. Sex partner support, drug use and sex risk among HIV-negative non-injecting heroin users. AIDS Care 2002; 14: 801-813.

35. Friedman SR, et al. Social Networks, Drug Injectors' Lives, and HIVIAIDS. 1999, New York (NY): Springer-Verlag.

36. Des Jarlais DC, et al. Convergence of HIV seroprevalence among injecting and non-injecting drug users in New York city. AIDS 2007; 21: 231-235.

37. Mathers BM, et al. HIV prevention, treatment, and care services for people who inject drugs: a systematic review of global, regional, and national coverage. Lancet 2010; 375: 1014-1028.

38. Maslow CB, et al. Changes in HIV seroprevalence and related behaviors among male injection drug users who do and do not have sex with men: New York city, 1990-1999. American Journal of Public Health 2002; 92: 382-384.
39. Des Jarlais DC, et al. Gender and age patterns in HSV-2 and HIV infection among non-injecting drug users in new york city. Sexually Transmitted Diseases 2010; 37: 637-643.

40. Bell AV, Ompad D, Sherman SG. Sexual and drug risk behaviors among women who have sex with women. American Journal of Public Health 2006; 96: 1066-1072.

41. Finlayson TJ, et al. HIV risk, prevention, and testing behaviors among men who have sex with men - national HIV behavioral surveillance system, 21 U.S. cities, United States, 2008. Morbidity and Mortality Weekly Report 2011; 60: 1-34.

42. Leigh BC, Temple MT, Trocki KF. The sexual behavior of us adults: results from a national survey. American Journal of Public Health 1993; 83: 1400-1408.

43. Lemp GF, et al. HIV seroprevalence and risk behaviors among lesbians and bisexual women in San Francisco and Berkeley, California. American Journal of Public Health 1995; 85: 1549-1552.

44. Arasteh K, Des Jarlais DC, Perlis TE. Alcohol and HIV sexual risk behaviors among injection drug users. Drug and Alcohol Dependence 2008; 95: 54-61.

45. Kral AH, et al. HIV risk profile of drug-using women who have sex with women in 19 United States cities. Journal of Acquired Immune Deficiency Syndromes and Human Retrovirology 1997; 16: 211-217.

46. Centers for Disease Control and Prevention (CDC). HIV infection and HIV-associated behaviors among injecting drug users - 20 cities, United States, 2009. Morbidity and Mortality Weekly Report 2012; 61: 133-138.

47. Arroyo J, et al. Re-thinking simulation: a methodological approach for the application of data mining in agentbased modelling. Computational and Mathematical Organization Theory 2010; 16: 416-435.

48. Windrum P, Fagiolo G, Moneta A. Empirical validation of agent-based models: alternatives and prospects. Journal of Artificial Societies and Social Simulation 2007; 10.

49. Centers for Disease Control and Prevention. Prevalence and awareness of HIV infection among men who have sex with men -21 cities, United States, 2008. Morbidity and Mortality Weekly Report 2010; 59: 1201-1207.

50. Jenness SM, et al. Heterosexual HIV and sexual partnerships between injection drug users and noninjection drug users. AIDS Patient Care STDS 2010; 24: 175181.

51. Manning SE, et al. Estimation of HIV prevalence, risk factors, and testing frequency among sexually active men who have sex with men, aged 18-64 years New York city, 2002. Journal of Urban Health 2007; 84: $212-225$.

52. Ompad DC, et al. HIV risk behaviors among young drug using women who have sex with women (WSWS) in New York city. Substance Use \& Misuse 2011; 46: 274-284.

53. Strathdee SA, Sherman SG. The role of sexual transmission of HIV infection among injection and non-injection drug users. Journal of Urban Health 2003; 80: iii7-iii14.

54. Torian LV, Bennani Y, Frieden TR. What is the true prevalence of HIV in New York city: estimating the 
number of undiagnosed and unreported persons living with HIV and AIDS, 2003. In 12th Conference on Retroviruses \& Opportunistic Infections. Boston, MA, 2005.

55. Tortu S, et al. Women's drug injection practices in east Harlem: an event analysis in a high-risk community. AIDS and Behavior 2003; 7: 317-328.

56. Lucas GM, et al. Detrimental effects of continued illicit drug use on the treatment of HIV-1 infection. Journal of Acquired Immune Deficiency Syndromes 2001; 27: 251-259.

57. Gardner EM, et al. The spectrum of engagement in HIV care and its relevance to test-and-treat strategies for prevention of HIV infection. Clinical Infectious Diseases 2011; 52: 793-800.

58. Kral AH, et al. HIV prevalence and risk behaviors among men who have sex with men and inject drugs in San Francisco. Journal of Urban Health 2005; 82: i43-i50.

59. Knowlton AR, et al. Antiretroviral use among active injection-drug users: the role of patient-provider engagement and structural factors. AIDS Patient Care STDS 2010; 24: 421-428.

60. Copeland L, et al. Changing patterns in causes of death in a cohort of injecting drug users, 1980-2001. Archives of Internal Medicine 2004; 164: 1214-1220.

61. New York City Department of Health and Mental Hygiene. Summary of vital statistics 2009: The city of New York. 2010 (http://www.nyc.gov/html/doh/downloads/pdf/vs/2009sum.pdf). Accessed 10 February 2013.

62. van Haastrecht HJ, et al. Predictors of mortality in the amsterdam cohort of human immunodeficiency virus (HIV)-positive and HIV-negative drug users. American Journal of Epidemiology 1996; 143: 380-391.

63. Kohli R, et al. Mortality in an urban cohort of HIV-infected and at-risk drug users in the era of highly active antiretroviral therapy. Clinical Infectious Diseases 2005; 41: 864-872.

64. Zaccarelli M, et al. Impact of HIV infection on non-AIDS mortality among Italian injecting drug users. AIDS 1994; 8: 345-350.

65. Mocroft A, et al. Changes in the cause of death among HIV positive subjects across europe: results from the EuroSIDA study. AIDS 2002; 16: 1663-1671.

66. CASCADE Collaboration. Determinants of survival following HIV-1 seroconversion after the introduction of HAART. Lancet 2003; 362: 1267-1274.

67. Egger M, et al. Prognosis of HIV-1-infected patients starting highly active antiretroviral therapy: a collaborative analysis of prospective studies. Lancet 2002; 360: 119-129.

68. Mocroft A, et al. Decline in the aids and death rates in the eurosida study: an observational study. Lancet 2003; 362: 22-29.

69. Wood E, et al. Highly active antiretroviral therapy and survival in HIV-infected injection drug users. Journal of the American Medical Association 2008; 300: 550554.

70. Brown LS Jr, Siddiqui NS, Chu AF. Natural history of HIV-1 infection and predictors of survival in a cohort of HIV-1 seropositive injecting drug users. Journal of the National Medical Association 1996; 88: 37-42.

71. Sackoff JE, et al. Causes of death among persons with aids in the era of highly active antiretroviral therapy: New York city. Annals of Internal Medicine 2006; 145: 397-406.

72. Vlahov D, et al. Effectiveness of highly active antiretroviral therapy among injection drug users with late-stage human immunodeficiency virus infection. American Journal of Epidemiology 2005; 161: 999-1012.

73. Marks G, et al. Meta-analysis of high-risk sexual behavior in persons aware and unaware they are infected with HIV in the united states: implications for HIV prevention programs. Journal of Acquired Immune Deficiency Syndromes 2005; 39: 446-453.

74. Ostrow DE, et al. Attitudes towards highly active antiretroviral therapy are associated with sexual risk taking among HIV-infected and uninfected homosexual men. AIDS 2002; 16: 775-780.

75. van Kesteren NM, Hospers HJ, Kok G. Sexual risk behavior among HIV-positive men who have sex with men: a literature review. Patient Education and Counseling 2007; 65: 5-20.

76. Friedman SR, et al. Consistent condom use in relationships between seropositive injecting drug users and sex partners who do not inject drugs. AIDS 1994; 8: $357-$ 362.

77. Vanichseni S, et al. Condom use with primary partners among injecting drug users in Bangkok, Thailand and New York city, United States. AIDS 1993; 7: 887-891.

78. Cooper HL, et al. Spatial access to syringe exchange programs and pharmacies selling over-the-counter syringes as predictors of drug injectors' use of sterile syringes. American Journal of Public Health 2011; 101: $1118-1125$.

79. Metzger DS, et al. Human immunodeficiency virus seroconversion among intravenous drug users in- and out-of-treatment: an 18-month prospective follow-up. Journal of Acquired Immune Deficiency Syndromes 1993; 6: 1049-1056.

80. Gowing $\mathbf{L}$, et al. Substitution treatment of injecting opioid users for prevention of HIV infection. Cochrane Database of Systematic Reviews 2008; Issue 2, Art. No.: CD004145: CD004145.

81. Galai N, et al. Longitudinal patterns of drug injection behavior in the alive study cohort, 1988-2000: description and determinants. American Journal of Epidemiology 2003; 158: 695-704.

82. Kottiri BJ, et al. Risk networks and racial/ethnic differences in the prevalence of HIV infection among injection drug users. Journal of Acquired Immune Deficiency Syndromes 2002; 30: 95-104.

83. Latkin CA, et al. Norms, social networks, and HIV-related risk behaviors among urban disadvantaged drug users. Social Science \& Medicine 2003; 56: 465 476.

84. Friedman SR, et al. Some data-driven reflections on priorities in aids network research. AIDS and Behavior 2007; 11: 641-651. 
85. Pathela $\mathbf{P}$, et al. Discordance between sexual behavior and self-reported sexual identity: a population-based survey of New York city men. Annals of Internal Medicine 2006; 145: 416-425.

86. Catania JA, et al. The continuing HIV epidemic among men who have sex with men. American Journal of Public Health 2001; 91: 907-914.

87. Sherman SG, Latkin CA. Intimate relationship characteristics associated with condom use among drug users and their sex partners: a multilevel analysis. Drug and Alcohol Dependence 2001; 64: 97-104.

88. Knight KR, et al. Sexual transmission risk behavior reported among behaviorally bisexual HIV-positive injection drug-using men. Journal of Acquired Immune Deficiency Syndromes 2007; 46 (Suppl. 2): S80-87.

89. Booth RE, Crowley TJ, Zhang Y. Substance abuse treatment entry, retention and effectiveness: Out-oftreatment opiate injection drug users. Drug and Alcohol Dependence 1996; 42: 11-20.

90. Hagan H, et al. Reduced injection frequency and increased entry and retention in drug treatment associated with needle-exchange participation in seattle drug injectors. Journal of Substance Abuse Treatment 2000; 19: 247-252.

91. Heimer R. Can syringe exchange serve as a conduit to substance abuse treatment? Journal of Substance Abuse Treatment 1998; 15: 183-191.

92. Strathdee SA, et al. Needle-exchange attendance and health care utilization promote entry into detoxification. Journal of Urban Health 1999; 76: 448460.

93. Rawson R, et al. Methamphetamine and cocaine users: differences in characteristics and treatment retention. Journal of Psychoactive Drugs 2000; 32: 233-238.

94. Brooner R, et al. Drug abuse treatment success among needle exchange participants. Public Health Report 1998; 113: 129-139.

95. Pathela P, et al. Discordance between sexual behavior and self-reported sexual identity: a population-based survey of new york city men. Annals of Internal Medicine 2006; 145: 416-425.

96. Heimer R, et al. Assessment of HIV testing of urban injection drug users: implications for expansion of HIV testing and prevention efforts. American Journal of Public Health 2007; 97: 110-116.

97. Anderson JE, Carey JW, Taveras S. HIV testing among the general us population and persons at increased risk: information from national surveys, 1987-1996. American Journal of Public Health 2000; 90: 1089-1095.

98. Celentano DD, et al. Time to initiating highly active antiretroviral therapy among HIV-infected injection drug users. AIDS 2001; 15: 1707-1715.

99. McGowan CC, et al. Drug use and receipt of highly active antiretroviral therapy among HIV-infected persons in two U.S. Clinic cohorts. PLOS ONE 2011; 6: e18462.

100. Cole SR, et al. Effect of highly active antiretroviral therapy on time to acquired immunodeficiency syndrome or death using marginal structural models. American Journal of Epidemiology 2003; 158: 687-694.
101. Uhlmann S, et al. Methadone maintenance therapy promotes initiation of antiretroviral therapy among injection drug users. Addiction 2010; 105: 907-913.

102. Ahdieh-Grant L, et al. Factors and temporal trends associated with highly active antiretroviral therapy discontinuation in the women's interagency HIV study. Journal of Acquired Immune Deficiency Syndromes 2005; 38: 500-503.

103. Li X, et al. Interruption and discontinuation of highly active antiretroviral therapy in the multicenter aids cohort study. Journal of Acquired Immune Deficiency Syndromes 2005; 38: 320-328.

104. Morris JD, et al. Injection drug use and patterns of highly active antiretroviral therapy use: an analysis of alive, wihs, and macs cohorts. AIDS Research and Therapy 2007; 4: 12.

105. Zaccarelli M, et al. Factors related to virologic failure among HIV-positive injecting drug users treated with combination antiretroviral therapy including two nucleoside reverse transcriptase inhibitors and nevirapine. AIDS Patient Care STDS 2002; 16: 67-73.

106. Kerr T, et al. Determinants of haart discontinuation among injection drug users. AIDS Care 2005; 17: 539-549.

107. Malta M, et al. Adherence to antiretroviral therapy among HIV-infected drug users: a meta-analysis. AIDS and Behavior 2010; 14: 731-747.

108. Ortego C, et al. Adherence to highly active antiretroviral therapy (HAART): a meta-analysis. AIDS and Behavior 2011; 15: 1381-1396.

109. Gallagher KM, et al. Behavioral surveillance among people at risk for HIV infection in the U.S.: the national HIV behavioral surveillance system. Public Health Report 2007; 122: 32-38.

110. Hilbe J. Negative Binomial Regression. Cambridge: Cambridge University Press, 2007.

111. Hamilton DT, Handcock MS, Morris M. Degree distributions in sexual networks: a framework for evaluating evidence. Sexually Transmitted Diseases 2008; 35: $30-40$.

112. Cohen MS, et al. Acute HIV-1 infection. New England Journal of Medicine 2011; 364: 1943-1954.

113. Wawer MJ, et al. Rates of HIV-1 transmission per coital act, by stage of HIV-1 infection, in rakai, uganda. Journal of Infectious Diseases 2005; 191: 1403-1409.

114. Granich RM, et al. Universal voluntary HIV testing with immediate antiretroviral therapy as a strategy for elimination of HIV transmission: a mathematical model. Lancet 2009; 373: 48-57.

115. Kaplan EH, Heimer R. A model-based estimate of HIV infectivity via needle sharing. Journal of Acquired Immune Deficiency Syndromes 1992; 5: 1116-1118.

116. Bangsberg DR, et al. Adherence to protease inhibitors, HIV-1 viral load, and development of drug resistance in an indigent population. AIDS 2000; 14: 357-366.

117. Vittinghoff $\mathbf{E}$, et al. Per-contact risk of human immunodeficiency virus transmission between male sexual partners. American Journal of Epidemiology 1999; 150: $306-311$. 
118. Royce RA, et al. Sexual transmission of HIV. New England Journal of Medicine 1997; 336: 1072-1078.

119. Baggaley RF, White RG, Boily MC. HIV transmission risk through anal intercourse: systematic review, meta-analysis and implications for HIV prevention. International Journal of Epidemiology 2010; 39: 10481063.

120. Gray RH, et al. Probability of HIV-1 transmission per coital act in monogamous, heterosexual, HIV-1discordant couples in Rakai, Uganda. Lancet 2001; 357: 1149-1153.

121. Quinn TC, et al. Viral load and heterosexual transmission of human immunodeficiency virus type 1. Rakai project study group. New England Journal of Medicine 2000; 342: 921-929.

122. Moss AR, Bacchetti P. Natural history of HIV infection. AIDS 1989; 3: 55-61.

123. Bangsberg DR, et al. Non-adherence to highly active antiretroviral therapy predicts progression to aids. AIDS 2001; 15: 1181-1183.

124. Raboud JM, et al. The impact of needle-exchange programs on the spread of HIV among injection drug users: a simulation study. Journal of Urban Health 2003; 80: 302-320.

125. Vickerman $\mathbf{P}$, Watts $\mathbf{C}$. The impact of an HIV prevention intervention for injecting drug users in Svetlogorsk, Belarus: model predictions. International Journal of Drug Policy 2002; 13: 149-164.

126. Handcock MS, Jones JH. Likelihood-based inference for stochastic models of sexual network formation. Theoretical Population Biology 2004; 65: 413-422.

127. Fraser C, et al. Variation in HIV-1 set-point viral load: epidemiological analysis and an evolutionary hypothesis. Proceedings of the National Academy of Sciences USA 2007; 104: 17441-17446.

128. Rangsin R, et al. The natural history of HIV-1 infection in young Thai men after seroconversion. Journal of Acquired Immune Deficiency Syndromes 2004; 36: 622-629.

129. Simon V, Ho DD, Abdool Karim Q. HIV/aids epidemiology, pathogenesis, prevention, and treatment. Lancet 2006; 368: 489-504.

130. Rodriguez RJ, et al. Comparison of serum and plasma viral rna measurements in primary and chronic human immunodeficiency virus type 1 infection. Journal of Acquired Immune Deficiency Syndromes and Human Retrovirology 1997; 15: 49-53.

131. Keele BF, et al. Identification and characterization of transmitted and early founder virus envelopes in primary HIV-1 infection. Proceedings of the National Academy of Sciences USA 2008; 105: 7552-7557.

132. Lee HY, et al. Modeling sequence evolution in acute HIV-1 infection. Journal of Theoretical Biology 2009; 261: 341-360.

133. Wilson DP, et al. Relation between HIV viral load and infectiousness: a model-based analysis. Lancet 2008; 372: 314-320.

134. Patel P, et al. Estimating per-act HIV transmission risk: a systematic review. AIDS 2014; 28: 1509-1519.
135. Samson M, et al. Resistance to HIV-1 infection in caucasian individuals bearing mutant alleles of the CCR-5 chemokine receptor gene. Nature 1996; 382: 722-725.

136. DePadilla L, Elifson KW, Sterk CE. Beyond sexual partnerships: the lack of condom use during vaginal sex with steady partners. International Public Health Journal 2012; 4: 435-446.

137. Bouhnik AD, et al. Unprotected sex in regular partnerships among homosexual men living with HIV: a comparison between sero-nonconcordant and seroconcordant couples (anrs-en12-vespa study). AIDS 2007; 21: S43-48.

138. Senn TE, et al. Sexual partner concurrency among STI clinic patients with a steady partner: correlates and associations with condom use. Sexually Transmitted Infection 2009; 85: 343-347.

139. Lau JT, et al. Sexual mixing and condom use with different types of sex partners among noninstitutionalized sexually active female injecting drug users in Sichuan, China. AIDS and Behavior 2011; 15: $86-94$.

140. Harris M, Rhodes T. Injecting practices in sexual partnerships: hepatitis $\mathrm{C}$ transmission potentials in a 'risk equivalence' framework. Drug and Alcohol Dependence 2013; 132: 617-623.

141. van Rossum G, Drake FL. Python Reference Manual. Python Labs: VA, 2001.

142. Des Jarlais DC, et al. HIV incidence among injection drug users in New York city, 1990 to 2002: use of serologic test algorithm to assess expansion of HIV prevention services. American Journal of Public Health 2005; 95: 1439-1444.

143. Pearson K. On the criterion that a given system of deviations from the probable in the case of a correlated system of variables is such that it can be reasonably supposed to have arisen from random sampling. Philosophical Magazine Series 5 1900; 50: 57-175.

144. Fone D, et al. Systematic review of the use and value of computer simulation modelling in population health and health care delivery. Journal of Public Health 2003; 25: 325-335.

145. Philips Z, et al. Good practice guidelines for decision-analytic modelling in health technology assessment: a review and consolidation of quality assessment. Pharmacoeconomics 2006; 24: 355-371.

146. Rutter CM, Zaslavsky AM, Feuer EJ. Dynamic microsimulation models for health outcomes: a review. Medical Decision Making 2011; 31: 10-18.

147. Kretzschmar M, Wiessing LG. Modelling the spread of HIV in social networks of injecting drug users. AIDS 1998; 12: 801-811.

148. Landovitz RJ, et al. A novel combination HIV prevention strategy: post-exposure prophylaxis with contingency management for substance abuse treatment among methamphetamine-using men who have sex with men. AIDS Patient Care STDS 2012; 26: 320 328.

149. McGowan I. An overview of antiretroviral preexposure prophylaxis of HIV infection. American 
Journal of Reproductive Immunology 2014; 71: 624 630.

150. Friedman SR, et al. Network-related mechanisms may help explain long-term HIV-1 seroprevalence levels that remain high but do not approach populationgroup saturation. American Journal of Epidemiology 2000; 152: 913-922.
151. Khan B, et al. Network firewall dynamics and the subsaturation stabilization of HIV. Discrete Dynamics in Nature and Society 2013; 2013: 720818.

152. Bellan SE, et al. Reassessment of HIV-1 acute phase infectivity: accounting for heterogeneity and study design with simulated cohorts. PLOS Medicine 2015; 12: e1001801. 